\title{
Estágios, identidade e formação do professor de matemática em tempos de mudanças
}

\author{
Erika Barroso Dauanny*
}

\section{Resumo}

Este artigo apresenta uma reflexão sobre o estágio na formação inicial universitária do professor da Educação Básica, bem como analisa as possiblidades de sua contribuição para a construção da identidade docente, em especial para o professor de Matemática. Partindo da compreensão de diversos autores sobre as mudanças que têm sido impostas à realidade profissional docente, entende ser necessária uma formação que considere o professor como um intelectual crítico reflexivo. Esse conceito traz a reflexão crítica subsidiada pela teoria, que permite aos professores avançarem num processo de transformação da prática pedagógica, mediante sua própria transformação. Uma reflexão que exige uma sólida formação teórica que dê condições ao sujeito de promover mudanças em seu fazer pedagógico. A concepção do professor como intelectual crítico reflexivo vai ao encontro de orientações para a formação docente oriundas de pesquisas que procuram olhar a formação do professor tendo o estágio como elemento central dessa formação. Enquanto uma atividade teórico-prática, uma atitude investigativa que envolve estudos, análise, problematização, reflexão e proposição de soluções sobre o ensinar e o aprender, sobre o trabalho docente e sobre as práticas institucionais situadas em seus contextos sociais, históricos e culturais; o estágio se constitui um espaço, por excelência, em que poderão ser tecidas as bases identitárias da profissão docente.

Palavras-chave: Estágio; Formação inicial do professor de Matemática; Professor intelectual crítico reflexivo; Identidade docente.

Professora da Universidade do Estado de Minas Gerais - UEMG-Ibirité. Integrante dos grupos de pesquisa: Grupo de Estudos e Pesquisas sobre a Formação do Educador (GEPEFE-FE-USP) e do Laboratório de Estudos sobre a Docência (LEDOC-UEMG). Brasil. E-mail: erikablk@yahoo.com.br 


\section{Introdução}

Qual o atual contexto de atuação do professor da Educação Básica? O que a realidade profissional docente demanda para a profissão, a formação e a identidade docente? Que mudanças têm se apresentado no contexto da atuação docente e, que exigências essas mudanças apresentam para a profissão, a formação e a identidade docente?

Até a década de 50, em função da configuração socioescolar, a posição social dos professores, a sua imagem na opinião pública e o seu trabalho na sala de aula eram claramente definidos e estáveis. Nessa época, o professor já era mal pago, mas era respeitado e sabia qual era a sua função social e quais deveriam ser as suas práticas em sala de aula. Entretanto, essa configuração histórica muda por inteiro a partir dos anos 60 e 70 do século XX e, na maioria dos países, em especial no Brasil, a escola passa a ser pensada na perspectiva do desenvolvimento econômico e social conforme Charlot (2008).

Nas décadas de 80 e 90, somam-se às mudanças anteriores aquelas que decorrem das novas lógicas neoliberais, impondo a sua versão da modernização econômica e social. Para essa ideologia a "lei do mercado" é o melhor meio, e mesmo o único, para alcançar eficácia e a qualidade. Multiplicam-se assim as privatizações, quer seja do ensino fundamental, médio e superior.

Da perspectiva do neoliberalismo decorre toda uma lógica de fazer educação com consequências nefastas para a mesma (SAVIANI, 2009; FREITAS, 2012, 2020; CHARLOT, 2008).

[...] ao mesmo tempo em que se proclamam aos quatro ventos as virtudes da educação exaltando sua importância decisiva num tipo de sociedade como esta em que vivemos, classificada como 'sociedade do conhecimento', as políticas predominantes se pautam pela busca da redução de custos, cortando investimentos (SAVIANI, 2009, p.153).

Nesse contexto, o professor enfrenta contradições que decorrem da contemporaneidade econômica, social e cultural, além das tensões inerentes ao próprio ato de educar e ensinar. As avaliações nacionais e internacionais que norteiam o ensino médio, o ensino fundamental e às vezes a educação infantil, acentuam a focalização dos alunos e dos professores sobre a nota. "O próprio professor encarna essa contradição radical: sonha em transmitir saberes e formar jovens, mas vive dando notas a alunos" (CHARLOT, 2008, p. 21). 
Essa forma de pensar a educação já havia sido detectada nos anos de 1980, e Saviani (1986) a denominou de "pedagogia tecnicista". Para Freitas,

O tecnicismo se apresenta, hoje, sob a forma de uma 'teoria da responsabilização', meritocrática e gerencialista, onde se propõe a mesma racionalidade técnica de antes na forma de 'standards', ou expectativas de aprendizagens medidas em testes padronizados, com ênfase nos processos de gerenciamento da força de trabalho da escola (controle pelo processo, bônus e punições), ancorada nas mesmas concepções oriundas da psicologia behaviorista, fortalecida pela econometria, ciências da informação e de sistemas, elevadas à condição de pilares da educação contemporânea. Denominamos esta formulação de 'neotecnicismo' (FREITAS, 2012, p. 383).

Entre as consequências dessas políticas, tem-se, segundo Freitas (2012, 2020), o estreitamento curricular, competição entre profissionais da escola, pressão sobre o desempenho dos alunos e preparação para os testes, fraudes, aumento da segregação socioeconômica no território, aumento da segregação econômica dentro da escola, precarização da formação do professor, destruição moral do professor, destruição do sistema público de ensino, ameaça à própria noção de democracia liberal.

Embora, essas mudanças venham de longa data, o bombardeamento da educação por uma perspectiva mercadológica, concorrencial, numa visão de sociedade que valoriza o individualismo e a meritocracia tem se intensificado a cada dia. A convivência humana é posta de lado em nome do individualismo. Desigualdades sociais são tratadas como desigualdades de mérito e nessa perspectiva o Estado não assume a Educação e busca passá-la à iniciativa privada, por considerar que nas empresas privadas a concorrência ficará garantida. A inclusão, atuação colaborativa, parceria, interação, construção coletiva não têm lugar nessa perspectiva meritocrática, individualistas e concorrencial (CHARLOT, 2008; FREITAS, 2012, 2020). Que professor é necessário formar para fazer frente a essas mudanças que vêm sendo impostas à educação, pelas políticas neoliberais, cada vez de forma mais radical?

Em outra perspectiva de análise, Pimenta (2009a) e Pimenta e Lima (2017), avaliam que o quadro atual da formação docente contrasta com as novas exigências hoje demandadas para a profissão, a formação e a identidade docente na sociedade brasileira contemporânea, em especial pelas exigências advindas do crescimento quantitativo dos sistemas de ensino. Esse resultado formativo (qualitativo) não se mostra, segundo as autoras, adequado às exigências da população envolvida, nem às exigências das demandas sociais. $\mathrm{O}$ que coloca a importância de definir nova identidade profissional do professor (PIMENTA, 2009a, p. 19). 
[...] os cursos de formação, ao desenvolverem um currículo formal com conteúdos e atividades de estágio distanciados da realidade das escolas, numa perspectiva burocrática e cartorial que não dá conta de captar as contradições presentes na prática social de educar, pouco têm contribuído para gestar uma nova identidade do profissional docente (PIMENTA, 2009a, p. 16).

Nesse sentido, Pimenta (2009a) reafirma a necessidade de ressignificar os cursos de licenciatura bem como a identidade do professor. Do ponto de vista teórico-metodológico, "os cursos de licenciatura precisam ser revistos a partir de três premissas: a estreita vinculação entre os conteúdos específicos e os pedagógicos; o conhecimento que se produz de forma construtiva e a íntima articulação entre teoria e prática” (PIMENTA, 2009c, p.135).

Caminhando na mesma direção que Pimenta (2009a), Franco (2014, p. 8) afirma que, a prática do professor, "[...] exige dele um comportamento compromissado e atuante. Tudo nele precisa de empoderamento. As práticas impõem posicionamento, atitude, força e decisão. Fundamentalmente é exigido do professor trabalhar com as contradições." Diante dessa colocação, a autora questiona: “Como está o professor preparado para tal?"

As análises apresentadas, sobre as mudanças que ocorrem no contexto da atuação profissional docente - impostas à educação, pelas políticas neoliberais e as decorrentes do crescimento quantitativo dos sistemas de ensino - evidenciam as reais condições da profissão docente e trazem diversas questões para a formação desse profissional, tais como: Que espaços estão sendo abertos na universidade para a construção de uma cultura profissional docente requerida pelas atuais condições do trabalho docente? Como as práticas universitárias de formação estão considerando as contradições hoje presentes no cotidiano profissional docente? Que professor é necessário formar para fazer frente às demandas que dessas mudanças se originam? Nesse contexto, qual o lugar do estágio no processo de formação do professor? De que maneira o estágio como componente curricular pode contribuir na construção da identidade docente? Como se constrói a identidade docente?

Para refletirmos sobre essas questões, consideraremos como Rios que: “[...] a identidade não é algo estático, pronto. Ela é algo em permanente construção, que se dá em situação, num contexto social, a partir da interação dos indivíduos e dos grupos” (RIOS, 2014, p. 4) e que, a identidade do professor é construída ao longo da sua trajetória profissional do magistério. No entanto, é no processo de sua formação que são consolidadas as opções e intenções da profissão que o curso se propõe legitimar. 


\section{Das concepçōes necessárias: de professor, de formação e de estágio}

Considerando a complexidade da docência e diante dos desafios colocados pela realidade profissional docente, necessário se faz, refletir sobre que professor é necessário formar. A cada concepção de professor, corresponde uma determinada concepção de escola, de ensino, uma teoria do conhecimento e da sua transmissão e aprendizagem, uma concepção própria das relações entre teoria e prática, entre a investigação e a ação (PÉREZ-GOMEZ, 1992). Essa correspondência se faz também para diferentes concepções de estágio, e consequentemente para as diferentes posições que os estágios ocupam na formação do professor. Neste sentido, a seguir será analisada a correspondência em relação à concepção de professor que consideramos necessário formar, sua formação e o lugar do estágio na sua formação e a contribuição do estágio para a construção da identidade docente.

\section{O professor como um profissional intelectual crítico reflexivo}

O ensino, atividade característica do professor, é uma prática social complexa, que exige opções éticas e políticas conforme Pimenta e Lima (2017).

Ser professor requer saberes e conhecimentos científicos, pedagógicos, educacionais, sensibilidade da experiência, indagação teórica e criatividade, para fazer frente a situações únicas, ambíguas, incertas, conflitivas e, por vezes, violentas que marcam as situações de ensino nos contextos escolares e não escolares. É da natureza da atividade docente proceder à mediação reflexiva e crítica entre as transformações sociais concretas e a formação humana dos alunos, questionando os modos de pensar, sentir, agir e de produzir e distribuir conhecimentos (PIMENTA; LIMA, 2017, p. 14-15).

Nessa perspectiva a atividade docente é práxis, é sistemática e científica, é intencional conforme Pimenta (2009b) e, como define Silvestre (2011), fundamentando-se em Marx (1983). ${ }^{1}$

A forma como Marx esclarece a composição do trabalho torna possível associar esse conceito a qualquer atividade humana [...] incluindo então a atividade docente. Nessa perspectiva, toda atividade docente é desenvolvida tendo em vista atingir um fim: ensinar alguma coisa a alguém; [...] dessa forma, o trabalho do professor pode ser compreendido como um ofício, como um trabalho [...] que não pode prescindir de uma intencionalidade, por se tratar de um trabalho [...] que lida não com objetos naturais, mas com outros humanos. [...] Um trabalho que, ao transformar o objeto - o aluno e o próprio conhecimento - vai constituindo a identidade docente (SILVESTRE, 2011, p. 173). 
Na práxis, prática e teoria (ação e intenção) não se separam; é essa característica que permite compreendê-la como interferência no e sobre o real, como possibilidade de transformação daquilo que se almeja mudar (LIMA, 2012). Assim como Fiorentini (2007) escreve que a prática em si não é formadora, mas as relações (de reflexão e investigação) que estabelecemos com ela, Lima (2012, p.104) escreve que " $a$ teoria não leva à transformação da realidade, (e) a prática (por sua vez) também não fala por si mesma (ela precisa da teoria), o que nos leva ao conceito de práxis, entendida como ação transformadora do natural, do humano e social".

Considerando a complexidade da docência e diante dos desafios colocados pela realidade profissional docente, faz-se necessária uma formação que considere a atividade docente como práxis e o professor como um intelectual crítico reflexivo conforme Contreras (2002), Pimenta (2008), Ghedin (2008) e Zeichner (2008). Mas, o que significa considerar o professor como um profissional intelectual crítico reflexivo?

Conceber o trabalho dos professores como trabalho intelectual quer dizer, segundo Contreras,

[...] desenvolver um conhecimento sobre o ensino que reconheça e questione sua natureza socialmente construída e o modo pelo qual se relaciona com a ordem social, bem como analisar as possibilidades transformadoras implícitas no contexto social das aulas e do ensino (CONTRERAS, 2002, p. 157).

Para Ghedin, refletir criticamente significa:

[...] colocar-se no contexto de uma ação, na história da situação, participar em uma atividade social e tomar postura ante os problemas. [...] Um processo de reflexão crítica permitiria aos professores avançar num processo de transformação da prática pedagógica mediante sua própria transformação como intelectuais críticos [...]. A reflexão crítica apela a uma crítica da interiorização de valores sociais dominantes, como maneira de tomar consciência de suas origens e de seus efeitos (GHEDIN, 2008, p. 138-139).

Nesse sentido, a concepção de professor como um profissional intelectual crítico reflexivo considera que:

[...] o exercício da docência não se reduz à aplicação de modelos previamente estabelecidos, mas que, ao contrário, é construído na prática dos sujeitos-professores historicamente situados. Assim, um processo formativo mobilizaria os saberes da teoria da educação necessários à compreensão da prática docente, capazes de desenvolverem as competências e habilidades para que os professores investiguem a própria atividade docente e, a partir dela, constituam os seus saberes-fazeres docentes, num processo contínuo de construção de novos saberes (PIMENTA, 2005, p. 528). 
A referida concepção de professor entende que o exercício da docência não se reduz à aplicação de modelos preestabelecidos, pois dada a sua complexidade e dinamicidade, exige do professor um constante posicionamento diante das questões e desafios que se apresentam no cotidiano da profissão. Para cumprir essa exigência, o entendimento, a análise, a reflexão e a construção de alternativas e de respostas a essas questões e desafios são exercícios contínuos do fazer docente. Exercícios de produção de conhecimento, já que as respostas a esses desafios não estão prontas.

\section{Da formação}

A concepção do professor como intelectual crítico reflexivo está relacionada a uma lógica de formação profissional que reconhece professores e futuros professores como sujeitos de conhecimento e que considera que as transformações das práticas docentes só se efetivarão se o professor ampliar sua consciência sobre a própria prática, a de sala de aula e a da escola como um todo, o que pressupõe os conhecimentos teóricos e críticos sobre a realidade.

O movimento que permite ao professor refletir sobre o seu fazer docente e redimensionar a sua prática é o vivenciar da práxis. Esse movimento é contínuo, possibilita a unidade entre teoria e prática e é formativo ao possibilitar a construção de novos saberes sobre o fazer docente. Para esse movimento, é necessária a teoria e é necessária a prática. $\mathrm{O}$ conhecimento é necessário para promover a reflexão, para que o professor tenha clareza dos elementos que condicionam e afetam seu modo de agir e seja capaz de inserir mudanças onde se fizer necessário. Nessa perspectiva, um processo formativo inclui o exercício e o aprender dessa dinamicidade, desse movimento, como uma exigência do fazer docente. Este processo formativo, por sua vez, mobiliza os

[...] saberes teóricos e práticos capazes de propiciar o desenvolvimento das bases para que o professor investigue sua própria atividade e, a partir dela, constitua os seus saberes num processo contínuo, de modo a se colocar como sujeito de suas práticas, analista do contexto em que atua, articulador dos conhecimentos teóricos com as dinâmicas sociais e as necessidades de aprendizagens dos alunos (ALMEIDA, 2008, p. 477).

Assim, ao mobilizar a teoria necessária à compreensão da prática docente, bem como proporcionar a apropriação de um processo de investigação da própria prática docente, constitui-se um processo que é contínuo e é fonte contínua de construção de novos saberes. 
Um bom processo formativo do professor incluirá, portanto, uma consistente formação teórica que, de fato, o instrumentalize para uma reflexão crítica sobre $o$ fazer pedagógico, que dê condições ao sujeito de transformá-lo se assim o desejar.

Silvestre salienta que:

A presença de uma práxis formativa nos cursos de formação inicial deve ser pautada pelos objetivos da própria dinâmica social: formar um professor que, buscando sua profissionalização, possua consciência crítica de sua prática, no sentido de tornar-se autônomo, propor práticas coerentes e criativas, e que, assumindo uma personalidade investigativa, possibilite a emancipação de seus alunos e, pela atividade docente, vá se constituindo como profissional competente e comprometido com uma escola que, para além do acesso, permita a permanência dos alunos com a qualidade possível (SILVESTRE, 2011, p. 175-176).

Assim, uma formação inicial do professor que reconhece a capacidade do futuro professor de decidir, reconhece esse profissional como sujeito produtor de conhecimentos para a teoria e para a prática de ensinar e que valoriza de fato o trabalho docente se pautará no conceito de práxis conforme Pimenta (2009c):

O desenvolvimento profissional dos professores tem se constituído em objetivo de propostas educacionais que valorizam a sua formação não mais baseada na racionalidade técnica, que os considera como meros executores de decisões alheias, mas numa perspectiva que reconhece a sua capacidade de decidir. Ao confrontar suas ações cotidianas com as produções teóricas, impõe-se rever suas práticas e as teorias que as informa, pesquisando a prática e produzindo novos conhecimentos para a teoria e a prática de ensinar. Assim, as transformações das práticas docentes só se efetivam na medida em que o professor amplia sua consciência sobre a própria prática, a de sala de aula e a da escola como um todo, o que pressupõe os conhecimentos teóricos e críticos sobre a realidade. [...] valorizar o trabalho docente significa dotar os professores de perspectiva de análise, que os ajudem a compreender os contextos históricos, sociais, culturais, organizacionais nos quais se dá sua atividade docente (PIMENTA, 2009c, p. 133-134).

Ao considerar que os cursos de licenciatura precisam ser revistos, entre outros aspectos, a partir da articulação entre teoria e prática, Pimenta (2009c) ressalta a importância do estágio no processo de formação de professores para a efetivação da unidade entre teoria e prática. Segundo a autora, é no âmbito do processo educativo, que mais íntima se afirma a relação entre teoria e prática. Na sua essência, a educação é uma prática intrinsecamente intencionalizada pela teoria. Decorre dessa condição a atribuição de um lugar central ao estágio, no processo de formação do professor. 


\section{Do estágio na formação do professor}

Por muito tempo o estágio foi considerado a hora da prática, a parte prática dos cursos de formação de profissionais. Nessa perspectiva os cursos de formação profissional têm duas partes: uma teórica e outra prática, sendo que a prática ocupa um lugar de menor importância. Nessa concepção, os saberes disciplinares, em geral, não se relacionam com o campo de atuação profissional dos futuros formandos; o curso não fundamenta teoricamente a atuação do futuro professor, nem toma a prática como referência para a fundamentação. Os programas das disciplinas, os conteúdos e métodos não levam em consideração a questão: que profissional se quer formar? Por não fundamentar teoricamente a atuação do futuro profissional nem tomar a prática como referência para a fundamentação teórica, é um curso que "carece de teoria e de prática" (PIMENTA; LIMA, 2017, p. 26).

Ao analisarem diferentes concepções de estágio relacionadas a diferentes concepções de prática e de teoria, Pimenta e Lima (2017) chegam ao que seria a superação da fragmentação entre elas a partir do conceito de práxis, o que aponta para "o desenvolvimento do estágio como uma atitude investigativa, que envolve a reflexão e a intervenção na vida da escola, dos professores, dos alunos e da sociedade" (PIMENTA; LIMA, 2017, p. 27).

O estágio fundado na práxis tem importante contribuição na produção de saberes por futuros professores, referenciando a reflexão como meio de redimensionar e ressignificar a prática, segundo Lima e Aroeira (2011).

A concepção do professor como intelectual crítico e reflexivo vai ao encontro de orientações para a formação docente oriundas de pesquisas que procuram olhar a formação do professor tendo o estágio como elemento central dessa formação.

Nesse sentido,

O estágio, então, deixa de ser considerado apenas um dos componentes e mesmo um apêndice do currículo e passa a integrar o corpo de conhecimentos do curso de formação de professores. Poderá permear todas as disciplinas, além do seu espaço específico de análise e síntese no final do curso. Cabe-lhe desenvolver atividades que possibilitem o conhecimento, a análise, a reflexão do trabalho docente, das ações docentes, nas instituições, a fim de compreendê-las em sua historicidade, identificar seus resultados, os impasses que apresenta, as dificuldades. Dessa análise crítica, à luz dos saberes disciplinares, é possível apontar as transformações necessárias no trabalho docente, nas instituições (PIMENTA; LIMA, 2017, p. 47). 
Segundo as mesmas autoras, esse conhecimento envolve: o estudo, a análise, a problematização, a reflexão e a proposição de soluções às situações de ensinar e aprender; experimentar situações de ensinar, aprender a elaborar, executar e avaliar projetos de ensino; o conhecimento, a utilização de técnicas, métodos e estratégias de ensinar em situações diversas; a habilidade de leitura e reconhecimento das teorias presentes nas práticas pedagógicas das instituições escolares. Uma responsabilidade de todas as disciplinas do curso de formação, articuladas por um projeto político-pedagógico de formação de professores.

A perspectiva do professor intelectual, crítico reflexivo identifica o estágio como atitude investigativa, que envolve reflexão e investigação sobre os problemas da atividade docente com vistas à sua transformação. Conforme Lima (2012), o estágio, assim, é o lócus das reflexões sobre o professor e seu trabalho. É fazendo do estágio esse espaço de reflexão sobre a docência que este poderá contribuir na formação do professor intelectual crítico reflexivo, competente e ciente de sua função social. Nesse sentido, o estágio torna-se um espaço de produção de conhecimento sobre a profissão docente, o que envolve teoria, prática, reflexão, produção de conhecimento sobre o professor e sua profissão. Ou seja, o estágio é considerado uma atividade teórico-prática, onde teoria e prática são indissociáveis.

Nessa perspectiva "o conhecimento e a interpretação do real existente serão o ponto de partida dos cursos de formação, uma vez que se trata de possibilitar aos futuros professores as condições e os saberes necessários para sua atuação profissional" (PIMENTA; LIMA, 2017, p. 47).

Segundo as mesmas autoras, o estágio assim realizado permite que se traga a contribuição de pesquisas e o desenvolvimento das habilidades de pesquisa. Essa postura investigativa favorece a construção de projetos de pesquisa a partir do estágio. Portanto, poderá ocorrer, desde o início do curso, possibilitando que a relação entre os saberes teóricos e os saberes das práticas ocorra durante todo o percurso de formação, garantindo, inclusive, que os alunos aprimorem sua escolha de ser professores a partir do contato com as realidades de sua profissão, conforme as mesmas autoras.

Trata-se do conceito de estágio como campo de conhecimento, no dizer de Pimenta e Lima (2017), e que envolve estudos, análise, problematização, reflexão e proposição de soluções sobre o ensinar e o aprender, tendo como eixo a pesquisa 
sobre as ações pedagógicas, o trabalho docente e as práticas institucionais situadas em seus contextos sociais, históricos e culturais.

Como apontado por Pimenta (2009c), o estágio curricular supervisionado dos cursos de formação inicial universitária de professores é um espaço/tempo de formação que traz a possibilidade de aproximação da realidade profissional docente e a oportunidade de sobre ela refletir criticamente com vistas à construção de alternativas. Trata-se de um espaço que abre a possibilidade de captar as contradições presentes na prática social de educar, podendo contribuir para gestar uma nova identidade do profissional docente, conforme Pimenta (2009a).

Nos espaços/tempos do estágio, as realidades do ensino e das condições reais da profissão docente se apresentam, a olhos vistos, aos alunos estagiários e aos professores formadores da universidade. Como uma atividade teórico-prática, o estágio oferece a possibilidade de proceder à mediação reflexiva e crítica entre as transformações sociais concretas e a formação dos professores, como dizem Pimenta e Lima (2017).

Por possibilitar a articulação direta com as escolas e instâncias em que os professores atuarão, o estágio pode apresentar formas de estudo, análise e problematização dos saberes nelas praticados, contribuindo assim para a ressignificação dos cursos de licenciatura em uma questão central: a articulação entre teoria e prática.

Embora o estágio supervisionado seja apenas uma parte do curso de formação de professores, nele, "[...] encontramos as marcas do tempo que estamos vivendo, das políticas de educação, da legislação vigente, das atuais tendências pedagógicas e da ideologia” (ALMEIDA; LIMA; SILVA, 2002, p. 15).

A esse respeito, Gomes et al. ${ }^{2}$ escrevem que:

As escolas, em especial, as pertencentes às redes públicas de ensino, são campos privilegiados de aprendizagem prática das instituições formadoras de professores em nível superior, por serem lugares característicos da diversidade e onde os saberes profissionais se desenvolvem. Elas apresentam uma espessura própria, reunindo, no mesmo tempo e no mesmo espaço, um conjunto complexo de interesses conflitantes e expectativas diversas. Nesse ambiente estão dispostos os efeitos de regulações, orientações legais e políticas governamentais que se cruzam com práticas instituídas no cotidiano das organizações, que se enfrentam, por sua vez, com práticas instituintes, resultantes das disputas no interior e no exterior das escolas (GOMES et al., 2011, p. 24).

Se visto como campo de produção de conhecimento, o estágio torna-se o lugar de aprofundar as questões referentes aos saberes e fazeres da profissão docente. É 
o lugar privilegiado, em que o futuro professor pode se ver como "eterno estagiário" ou "eterno aprendiz" da profissão, como diz Lima (2012), entendendo o seu processo de formação profissional como sendo contínuo, de construção e dialético. Características essas que também devem estar presentes em seu processo formativo. Daí a necessidade de que, ao desenvolver o estágio, se tenha uma ideia clara a respeito da concepção de professor que se quer formar. No processo do estágio, a exigência do posicionamento se faz fortemente presente, visto que é um momento do processo formativo no qual o futuro professor se depara com a realidade profissional docente.

Silvestre (2011) associa a definição de estágio ao conceito de trabalho, na perspectiva do materialismo dialético, e, com isso, concebe o estágio, mais especificamente, o espaço de supervisão dos estágios como um espaço mobilizador da transformação das identidades e subjetividades e que deve ter no bojo de suas discussões a natureza da prática pedagógica.

O estágio é um espaço em que os alunos podem questionar e refletir sobre sua futura profissão de professor, a sua práxis, a identidade docente (LIMA, 2012). Assim, o estágio é uma atividade curricular chave para a concretização de um modelo formativo que melhor prepare o futuro professor para o enfrentamento das demandas da prática pedagógica. O estágio é, por excelência, um espaço em que poderão ser tecidas as bases identitárias da profissão docente (PIMENTA; LIMA, 2017).

Ghedin reflete sobre como o estágio poderá contribuir para a formação do professor-pesquisador como intelectual crítico e afirma que:

Ao denominar o desenvolvimento do estágio como atividade de pesquisa, assumimos a perspectiva da pesquisa como colaborativa e/ou pesquisa-ação, e entendemos que sua finalidade é criar uma cultura de análise das práticas que objetiva suas transformações pelos professores, com a colaboração dos professores da universidade e dos estagiários (GHEDIN, 2006, p. 239).

É preciso ressaltar que o estágio como pesquisa e a pesquisa no estágio aqui considerado não se confunde com qualquer pesquisa que se faça durante o estágio. De acordo com nossas observações em cursos de formação de professores, a expressão "estágio como pesquisa" tem sido utilizada de forma vaga, sem especificar que tipo de pesquisa ou a qual concepção de relação teoria e prática está se referindo, ou sem uma definição de qual professor se pretende formar. Dessa forma, o estágio como pesquisa tona-se algo muito vago e impreciso. Faz-se necessário, portanto, refletir sobre as condições nas quais a pesquisa no estágio traria contribuições para a formação do professor intelectual crítico reflexivo. 


\section{Pesquisas e práticas de estágio na formação do professor de intelectual crítico reflexivo}

Pesquisas e experiências recentes como Lima (2012), Leite (2008), Gomes (2011), Gomes et al. (2011), Ghedin e Almeida (2011), Ostetto (2011), Panizzolo (2011), Lima e Aroeira (2011), Filho, Lopes e Cavalcante (2011), Silvestre (2011), Nakano e Ancassuerd (2011), Almeida et al. (2011), Silvestre e Valente (2014) apresentam, relatam e discutem uma grande diversidade de questões relativas ao estágio, revelando a sua amplitude e as suas diversas dimensões formativas.

De um modo geral, esses trabalhos consideram um processo formativo de professores que ambiciona a formação de um profissional capaz de contextualizar histórica e politicamente o processo de ensino-aprendizagem, situando sua prática e compreendendo-a como uma prática social que envolve sujeitos e subjetividades e que, intencionalmente, deve intervir na realidade na qual se insere, tal como também considera o conceito do professor como profissional intelectual crítico reflexivo.

Entre outros autores, Ghedin (2006), Lima (2012) e Fiorentini (2004) escrevem sobre as condições necessárias para a realização do estágio como pesquisa na perspectiva da formação do professor intelectual crítico reflexivo. Eles ressaltam, por exemplo, a necessidade de formar comunidades de investigação e de se considerar o estagiário como sujeito da aprendizagem no processo de pesquisa.

\section{Os grupos colaborativos como possibilidade}

Segundo Ghedin (2006, p. 227),

O estágio vinculado ao processo de formação de professor-pesquisador implica formação de uma comunidade investigativa que, no coletivo, busca investigar as problemáticas que mais atingem a escola e exige uma alternativa, que pode ser elaborada em com a universidade.

O trabalho de Fiorentini (2010) traz contribuições para a efetivação das condições necessárias para a realização do estágio como pesquisa, na perspectiva da formação do professor intelectual crítico reflexivo, no que se refere a um planejamento coletivo apontado por Ghedin (2006), e da necessidade de considerar alunos estagiários e professores da Escola Básica também como sujeitos no processo formativo. Esse autor, defende que os professores da escola e da universidade e futuros docentes podem, juntos, aprender a enfrentar o desafio da escola atual. Isso implica, segun- 
do Fiorentini (2010, p. 579) "[...] constituir comunidades críticas e colaborativas de docentes - uma aliança entre formadores, pesquisadores, professores e futuros professores - que assumam a pesquisa como postura e prática social."

$\mathrm{O}$ referido autor destaca que, nessa metodologia de trabalho e de pesquisa, a teoria deixa de ser o ponto de partida para se tornar uma mediação importante e necessária em busca de entendimentos dos problemas trazidos pelos professores das escolas.

O grupo colaborativo, formado por formadores de professores (atuam em função da demanda dos professores da escola), docentes da escola (trazem problemas e desafios das práticas escolares) e futuros professores, estuda, problematiza, reflete, investiga e escreve sobre a complexidade de ensinar e aprender matemática nas escolas e negocia as práticas curriculares desejáveis e possíveis para cada realidade conforme Fiorentini (2010).

Uma condição também apontada por Fiorentini e Castro (2003) para que a formação docente e a respectiva produção de saberes aconteçam de modo efetivo é que haja um processo de reflexão. Esta aparece como parte do processo de formação profissional, no qual os saberes docentes são mobilizados, problematizados e ressignificados pelos futuros professores. A reflexão é compreendida pelos referidos autores,

[...] como um caminho passível de ruptura, principalmente com o pensamento simplificador, que busca indícios para compreender melhor o cotidiano escolar e desenvolver ações pedagógicas que integrem mais o aluno e o professor no processo de ensinar e aprender. (FIORENTINI;CASTRO, 2003, p.127)

Alves, Queirós e Batista (2017) partem do conceito de comunidade de práti$c a$, assim como fez Fiorentini (2010), e desenvolvem uma reflexão conceitual, da qual ressalta o valor formativos das comunidades de prática para a construção da identidade profissional de futuros professor em contexto de estágio, bem como os limites que essas podem encerrar. O potencial das comunidades de prática, é evidenciado no processo de construção da identidade profissional dos estagiários que nelas encontram um espaço de partilha e de reflexão que lhes permite construir e reconstruir concepções.

Para essas autoras, nos estágios, as comunidades de prática assumem-se como lugares privilegiados de partilha e construção de conhecimento, em resultado de interações estabelecidas entre os diferentes elementos, que fomentam o desenvolvimento profissional dos orientadores e a construção da identidade profissional 
do estudante estagiário. Através da imersão numa comunidade de prática e das constantes interações que daí advém, formais e informais, é possível enriquecer o estágio e o processo de construção da identidade profissional, "encontrado soluções em espaços, porventura, não antes explorados” (ALVES; QUEIRÓS; BATISTA, 2017, p. 174).

Trabalho como os citados anteriormente, evidenciam, entre as condições necessárias para a formação de um professor intelectual crítico reflexivo, um processo que envolve a fundamentação teórica, investigação, reflexão, colaboração, parceria, diálogo, interação como já apresentado neste texto.

Considerar o estágio como encontro de diferentes pessoas, com diferentes histórias e experiências significa que, para qualificá-lo, "o caminho é o aprofundamento das relações [...], cuja base só poderá ser o diálogo, a troca, a interlocução, conduzindo a todos para o 'fazer junto"' (OSTETTO, 2011, p. 83).

As relações sociais colaborativas, interativas e dialógicas, que permeiam os trabalhos anteriormente citados, constituem o que Santos (1992) chamou de relações sociais do tipo novo. Elas são radicalmente antagônicas às relações individualistas e competitivas que fundamentam as práticas pedagógicas capitalistas, excludentes e seletivas e foram criadas pelos trabalhadores em suas lutas autônomas, segundo o mesmo autor. A partir das novas relações sociais criadas pelos trabalhadores em luta, criam-se as condições sociais necessárias à produção de conhecimento e à transformação social.

Nesse sentido, as relações coletivas, colaborativas e igualitárias devem permear todo o processo formativo, possibilitando, conforme Rios (2014), que, no espaço de formação, os saberes específicos para a docência ganhem sua configuração.

A seguir, serão apresentados alguns dados de uma pesquisa que confirmam o estágio como um lugar privilegiado de reflexão e de construção e fortalecimento da identidade docente.

\section{A reflexão no estágio, o desejo ${ }^{3}$ de ser professor de Matemática e a contribuição do estágio para a construção da identidade docente}

Ao buscar compreender o estágio na formação inicial universitária como processo formativo e no contexto dos processos formativos do professor de Matemática para a Educação Básica, Dauanny (2015) parte das seguintes questões: Como o estágio 
está sendo considerado e desenvolvido no curso de licenciatura em Matemática? Qual a compreensão dos futuros professores, alunos do Curso de Licenciatura em Matemática, dos processos formativos relacionados ao estágio, por eles vivenciados, no sentido da contribuição desses processos para a sua formação como professores? Em quais condições o estágio constitui-se um processo formativo significativo no curso de licenciatura em Matemática? Que possibilidades formativas são criadas no processo de desenvolvimento do estágio curricular supervisionado?

A opção metodológica, da referida pesquisa, foi por uma pesquisa qualitativa apoiada em dados quantitativos. A base empírica escolhida para a realização da pesquisa foi o curso de Licenciatura em Matemática da Universidade de São Paulo, cujo Programa de Formação de Professores (PFPUSP, 2004) considera as concepções coerentes com as necessidades hoje colocadas para a formação de professores. Neste Programa a concepção de professor que se almeja formar pode ser identificada com a do professor intelectual crítico reflexivo, conforme considerado neste artigo.

Dentre os recursos utilizados para coleta de dados, Dauanny (2015) realizou: análise documental; observação por um período de dois anos (2011-2012) de momentos do processo de formação desenvolvido no Curso de Licenciatura em Matemática do IME-USP e relacionados ao estágio supervisionado, na universidade e em uma das escolas de Educação Básica onde alunos desenvolvem o estágio; questionários a uma amostra dos alunos do Curso de Licenciatura em Matemática do IME-USP; entrevistas com alunos do curso analisado e com um professor da escola de Educação Básica que recebeu alunos estagiários. Os vários instrumentos de coleta de dados foram utilizados de maneira complementar para a compreensão do estágio como processo formativo no contexto da formação inicial universitária do professor de Matemática da Educação Básica.

Os dados coletados e a análise estatística desenvolvida oferecem elementos para compreensão e interpretação do fenômeno educativo relativo à formação do professor. Neste artigo, será apresentado a análise estatística de alguns dados produzidos através do questionário respondido por alunos das licenciaturas da USP, e, em especial por alunos do curso de Licenciatura em Matemática, sujeitos desta pesquisa. A amostra é composta por 99 sujeitos, sendo 49 alunos provenientes de diversos cursos de licenciatura da USP e 50 alunos do curso de Licenciatura em Matemática do IME-USP. 
Na Licenciatura em Matemática do IME-USP, as 400 horas de estágio curricular supervisionado, obrigatório no curso, estão distribuídas entre oito disciplinas: as disciplinas do Bloco III, de Fundamentos Teóricos e Práticos da Educação (POEB - Política e Organização da Educação Básica no Brasil; Didática e Psicologia da Educação), obrigatórias para todas as licenciaturas da USP e oferecidas pela Faculdade de Educação e as do Bloco IV, de Fundamentos Metodológicos do Ensino (Experimentação e Modelagem; Estágio de Vivência e Investigação em Gestão Escolar e Políticas Públicas; Metodologia do Ensino da Matemática I e II e Projetos de Estágio) sendo as primeiras oferecidas pela FEUSP e a última pelo IME-USP.

Os dados, produzidos através do questionário, trazem a perspectiva dos alunos estagiários em relação às seguintes categorias: (A) Grau de contribuição dos conteúdos e atividades desenvolvidos em cada disciplina ${ }^{4}$ para análise e construção de alternativas frente às dificuldades que hoje se apresentam aos professores nas escolas; (B) Grau de contribuição de cada atividade ou estratégia de ensino desenvolvida nas disciplinas, para a formação de professores; (C) Espaço de reflexão, em cada uma das disciplinas, sobre as observações e outras atividades desenvolvidas durante o estágio; (D) Influência do estágio, desenvolvido nas disciplinas, no desejo de ser professor; (E) $\mathrm{O}$ fator que, na(s) disciplina(s), mais contribuiu para a formação.

Para este artigo destacaremos apenas aspectos dos dados relativos à categoria (B) Grau de contribuição de cada atividade ou estratégia de ensino desenvolvida nas disciplinas, para a formação de professores; e da categoria (D) Influência do estágio, desenvolvido nas disciplinas, no desejo de ser professor, bem como da relação entre elas.

Em relação à categoria (B), a atividade de Reflexão sobre as atividades e/ou observações desenvolvidas durante o estágio foi, percentualmente, a mais indicada, pelos futuros professores, de diversos cursos de licenciatura da USP, como tendo um Alto grau de contribuição para a formação dos mesmos. A reflexão foi apontada pelos futuros professores como núcleo essencial da formação de professores, como a variável mais importante que mexe com a formação dos professores. Assim considerada, o estágio deixa de ser a "hora da prática" para tornar-se uma atividade teórico-prática, um espaço tempo onde a teoria é indissociável da prática. O estágio é assim, ao mesmo tempo uma atividade teórica de conhecimento, fundamentação, diálogo e intervenção na realidade prática. 
Em relação à categoria (D) Influência do estágio, desenvolvido nas disciplinas, no desejo de ser professor, os dados revelam que o estágio tem forte influência no desejo ou opção de ser professor. A soma do percentual dos alunos, da licenciatura em Matemática, que tiveram influência do estágio no desejo de ser professor, seja uma influência positiva ou negativa corresponde a $62 \%$ nas disciplinas do Bloco III (Fundamentos Teóricos e Práticos da Educação) e 65\% nas disciplinas do Bloco IV (Fundamentos Metodológicos do Ensino).

Conforme Fischmann ${ }^{5}$ (1994, p.62) citado por Pimenta e Lima (2017, p.53): “A nossa identidade se constrói a partir da intersecção das circunstâncias que nos cercam com os desejos que trazemos." Neste sentido, com o intuito de entender melhor como o estágio pode influenciar ou não no "desejo de ser professor" e, em decorrência, a contribuição do estágio para a construção da identidade docente, foi realizado um estudo estatístico aprofundado sobre essa questão, considerando apenas os alunos da Licenciatura em Matemática. Assim, procedeu-se à análise das seguintes relações: De que maneira aspectos abordados pelo questionário se relacionavam com a influência do estágio no desejo de ser professor? O que é mais representativo para contribuir para que o estágio tenha influência positiva no desejo de ser professor?

A análise baseou-se na resposta dos alunos para a questão "Como o estágio desenvolvido (nas disciplinas dos Blocos Curriculares III e IV) influenciou o seu desejo de ser professor?", para a qual há três respostas possíveis: influenciou negativamente, não influenciou e influenciou positivamente.

O estudo estatístico aprofundado permitiu estimar as probabilidades e as chances de que um aluno que classifique de uma das três formas possíveis a influência do estágio no desejo de ser professor, venha também a dar determinadas respostas sobre questões relacionadas às disciplinas de cada bloco: contribuição dos conteúdos e atividades de cada disciplina para análise e construção de alternativas para as dificuldades que hoje se apresentam aos professores nas escolas; contribuição de cada atividade ou estratégia de ensino para a formação como professor; fator que nas disciplinas mais contribuiu com a formação como professor.

O resultado deste estudo estatístico para as disciplinas tanto do Bloco III (Fundamentos Teóricos e Práticos da Educação ) como para as disciplinas do Bloco IV (Fundamentos Metodológicos do Ensino) sugere que o aluno que julga o grau de contribuição da atividade reflexão sobre atividades e / ou observações desenvolvidas durante o estágio como alto tem probabilidade mais alta de considerar que o estágio 
influenciou positivamente no desejo de ser professor do que um aluno que não julga alto o grau de contribuição da atividade.

Um outro resultado significativo deste estudo estatístico aprofundado para as disciplinas do Bloco III, indica que: a chance de um aluno que julga o grau de contribuição da atividade reflexão sobre atividades e / ou observações desenvolvidas durante o estágio como alto considerar que o estágio influenciou positivamente no desejo de ser professor é de aproximadamente 25,44 vezes a chance de um aluno que não julga alto o grau de contribuição da atividade considerar que o estágio influenciou positivamente no desejo de ser professor, desde que sejam mantidas constantes as demais variáveis.

O mesmo estudo para as disciplinas do Bloco IV indica que essa chance é de aproximadamente 7,49 vezes. Ou seja: a chance de um aluno que julga $o$ grau de contribuição da atividade reflexão sobre atividades e / ou observações desenvolvidas durante o estágio como alto considerar que o estágio influenciou positivamente no desejo de ser professor é de aproximadamente 7,49 vezes a chance de um aluno que não julga alto o grau de contribuição da atividade considerar que o estágio influenciou positivamente no desejo de ser professor, desde que sejam mantidas constantes as demais variáveis.

Assim, do estudo estatístico aprofundando sobre a influência do estágio no desejo de ser professor, é possível concluir que a atividade de reflexão sobre as atividades e/ou observações desenvolvidas durante o estágio, quando tem sua contribuição avaliada como alta pelos futuros professores, aumenta a probabilidade de o estágio influenciar positivamente no desejo de ser professor, mais do que qualquer outra atividade ou disciplina quando estas também são avaliadas de modo positivo pelos alunos, ou seja, a atividade de reflexão sobre as atividades e/ou observações desenvolvidas durante o estágio, quando avaliada de maneira positiva pelos alunos, é o fator mais representativos em contribuir para que o estágio tenha influência positiva no desejo de ser professor.

De forma complementar, em seus depoimentos, os futuros professores relatam a existência de um importante e rico movimento de reflexão relacionado, não só às atividades de estágio, mas também aos saberes experienciais, seja promovido pelos professores responsáveis pelas disciplinas de estágio que cursaram ou por eles próprios. Evidenciam diferentes níveis da reflexão realizada. Em algumas situações observadas, parece que suas experiências e saberes foram problematizados e 
estudados. A reflexão desenvolvida parece ter trazido novos elementos aos futuros professores no sentido de os levarem a se recolocarem diante das experiências ou dos saberes, ou a ressignificarem saberes e experiências e, com isso, construírem possibilidades de superação de problemas aí identificados. Neste sentido, a reflexão, como parte integrante do estágio parece trazer elementos mobilizadores em relação ao desejo de ser professor.

\section{Considerações Finais}

A concepção de professor intelectual crítico reflexivo privilegiada nesta pesquisa, bem como a sua formação, tem a reflexão como uma categoria fundante. A prática educativa tem relações com o que acontece em outros âmbitos da sociedade. O processo reflexivo proporciona o entendimento das relações entre o que acontece na prática educativa e os seus determinantes externos. Nos estágios, os futuros professores e os professores formadores têm oportunidade de se depararem com a complexidade que caracteriza o cotidiano das escolas, e isso faz surgir oportunidades de refletir criticamente sobre essa realidade, de entender os seus determinantes, de compreender a complexidade das práticas institucionais e das ações aí praticadas e de construir alternativas para os problemas que aí se apresentam. Nesse sentido, o estágio é uma peça chave para a concretização de um modelo formativo que melhor prepare o futuro professor para o enfrentamento das demandas da prática pedagógica.

A teoria, nesse contexto, deve

[...] oferecer instrumentos e esquemas para análise e investigação que permitam questionar as práticas institucionalizadas e as ações dos sujeitos e, ao mesmo tempo, colocar elas próprias em questionamento, uma vez que as teorias são explicações sempre provisórias da realidade (PIMENTA; LIMA, 2017, p. 35).

Segundo as autoras, todas as disciplinas do curso de formação são responsáveis por trazer elementos que contribuam para as reflexões, o entendimento e a construção de alternativas para os problemas encontrados na realidade profissional docente. Todas são, ao mesmo tempo, "teóricas" e "práticas", na medida em que podem (e devem) oferecer conhecimentos e métodos para esse processo reflexivo.

Nessa perspectiva, o estágio deixa de ser a "hora da prática" para tornar-se uma atividade teórico-prática, um espaço/tempo em que a teoria é indissociável da práti- 
ca. O estágio passa a ser, ao mesmo tempo, uma atividade teórica de conhecimento, fundamentação, diálogo e intervenção na realidade prática. Essa perspectiva de estágio, de formação, é uma demanda que, segundo Dauanny (2015), está claramente colocada pelos alunos da Licenciatura em Matemática, em especial por aqueles que desejam ser professores. E como a docência, segundo a mesma pesquisa, não está descartada para a grande maioria desses alunos, a reflexão sobre as atividades desenvolvidas durante o estágio, mais do que qualquer outra atividade, aumenta a probabilidade de que esses alunos venham a assumir profissionalmente a docência. Assim, o estágio é, nas condições anteriormente apresentadas, por excelência, um espaço em que poderão ser tecidas as bases identitárias da profissão docente, pois, conforme Buriolla (1999, p.10)6 citado por Pimenta e Lima (2017, p. 51), "o estágio é o lócus onde a identidade profissional é gerada, construída e referida; volta-se para o desenvolvimento de uma ação vivenciada, reflexiva e crítica e, por isso, deve ser planejado gradativamente e sistematicamente com essa finalidade".

Entretanto, conforme aponta a pesquisa de Dauanny (2015), por falta de uma perspectiva coletiva, clara e firme com relação à qual professor se almeja formar, acaba-se perdendo oportunidades formativas oferecidas pelo estágio, como a de estudo e construção de conhecimento sobre a docência, sobre o ensino. Há de se considerar também que, para a explicitação das concepções a serem privilegiadas em um processo formativo, há necessidade de uma reflexão contínua sobre a ação de formação desenvolvida: Qual a identidade que o curso apresenta hoje? O que precisa mudar nessa identidade? entendendo que a identidade não é fixa, mas é construída historicamente pela ação de seus sujeitos (PIMENTA, 2001).

Diante disso, a formação propiciada pelo curso de formação de professores de Matemática pode resultar na construção de uma identidade frágil e fragmentada, formando um professor com uma postura insegura diante da realidade da Educação Básica. Uma realidade que, conforme vimos no início deste texto, exige posicionamento firme com vistas à sua necessária transformação. 


\section{Internships, identity and formation of the mathematics teacher in times of changes}

\section{Abstract}

This article presents a reflection on the internship in the initial university formation of the Basic Education teacher, as well as analyzes the possibilities of its contribution to the construction of the teaching identity, especially for the Mathematics teacher. Based on the understanding of several authors about the changes that have been imposed on the professional reality of teaching, it's understood that it's necessary a formation that considers the teacher as a reflective critical intellectual. This concept brings critical reflection supported by theory, which allows teachers to advance in a process of transforming pedagogical practice, through their own transformation. A reflection that requires a solid theoretical formation that allows the person to promote changes in his pedagogical practice. The conception of the teacher as a reflexive critical intellectual is in line with guidelines for teacher training that comes from research that understands the teacher formation with internship as the central element of this training. As a theoretical-practical activity, an investigative attitude that involves studies, analysis, problematization, reflection and proposition of solutions on teaching and learning, on teaching work and on institutional practices based in their social, historical and cultural contexts; the internship is a space, par excellence, in which the identity bases of the teaching profession can be built.

Keywords: Internship; Initial Math Teacher formation; Intellectual critical reflective teacher; teaching identity.

\section{Notas}

1 MARX, K. H. O capital: crítica da economia política. São Paulo: Abril, 1983. v. 1, t. 1.

2 Os autores descrevem, nesse trabalho, a experiência pioneira no Brasil do estágio como residência pedagógica, da qual participam. Trata-se de uma imersão no campo profissional capaz de corresponsabilizar não só a universidade, mas, sobretudo, as escolas-campo e seus profissionais, considerados colaboradores no processo de formação universitária.

3 Desejo entendido apenas como vontade de ser professor

4 Disciplinas responsáveis por orientar o estágio

5 FISCHMANN, R. Redefinição de público e do privado: contribuição para a reflexão educacional. In: ALVES, M. L. Escola: espaço de construção da cidadania. São Paulo: F.D.E, 1994.

6 BURIOLLA, M. A. F. O Estágio Supervisionado. São Paulo: Cortez Editora, 1999. 


\section{Referências}

ALMEIDA, A. M. B. de; LIMA, M. S. L.; SILVA, S. P. (Orgs.). Dialogando com a escola: reflexões do estágio e ação docente nos cursos de formação de professores. Fortaleza: Edições Demócrito Rocha, 2002.

ALMEIDA, E. de; GOMES, M. de O.; TINÓS, L. S. "Portfólios de aprendizagem": autonomia, corresponsabilização e avaliação formativa na formação de professores. In: GOMES, M. de O. (Org.). Estágios na formação de professores: possibilidades formativas entre ensino, pesquisa e extensão. São Paulo: Edições Loyola, 2011. p. 201-222.

ALMEIDA, M. I. de. Ensino com pesquisa na licenciatura como base da formação docente. In: TRANSVERSINI, C. et al. (Orgs.). Trajetórias e processos de ensinar e aprender: práticas e didáticas - Livro 2. Porto Alegre: EDIPUCRS, 2008. p. 473-487.

ALVES, M.; QUEIRÓS, P.; BATISTA, P. O valor formativo das comunidades de prática na construção da identidade profissional. Revista Portuguesa de Educação, 30(2), p.159-185, 2017.

CHARLOT, B. O professor na sociedade contemporânea: um trabalhador de contradição. Revista da FAEEBA - Educação e Contemporaneidade, Salvador, v. 17, n. 30, p. 17-31, jul./dez. 2008.

CONTRERAS, J. Autonomia de professores. São Paulo: Cortez, 2002.

DAUANNY, E. B. O estágio no contexto dos processos formativos dos professores de Matemática para a Educação Básica: entre o proposto e o vivido. 2015. 375f. Tese (Doutorado em Educação) - Faculdade de Educação, Universidade de São Paulo, São Paulo, 2015

FILHO, A. L. da S.; LOPES, F. M. N.; CAVALCANTE, M. M. D. A dimensão ontológica da trilogia ensino, pesquisa e extensão no estágio supervisionado. In GOMES, M. de O. (Org.). Estágios na formação de professores: possibilidades formativas entre ensino, pesquisa e extensão. São Paulo: Edições Loyola, 2011. p. 187-200.

FIORENTINI, D. A didática e a prática de ensino mediadas pela investigação sobre a prática. In: ROMANOWSKI, J.; JUNQUEIRA, S. (Orgs.). Conhecimento local e conhecimento universal: pesquisa, didática e ação docente. Curitiba: Champagnat, 2004. v. 1, p. 243-257.

FIORENTINI, D. Desenvolvimento profissional e comunidades investigativas. In: CUNHA, A. M. de O. et al. (Orgs.). Convergências e tensões no campo da formação e do trabalho docente. (Textos selecionados do XV ENDIPE). Belo Horizonte: Autêntica, 2010. p. 570-590.

FIORENTINI, D. Por uma formação realmente contínua e emancipadora do professor. In: ENEM ENCONTRO NACIONAL DE EDUCAÇÃO MATEMÁTICA, Diálogos entre a Pesquisa e a Prática Educativa, 9., 2007, Belo Horizonte. Belo Horizonte, 18 a 21 de julho de 2007.

FIORENTINI, D.; CASTRO, F. C. de. Tornando-se professor de matemática: o caso de Allan em prática de ensino e estágio supervisionado. In: FIORENTINI, D. Formação de professores de matemática: explorando novos caminhos com outros olhares. Campinas, SP: Mercado das Letras, 2003. p. 121-156.

FRANCO, M. A. S. Didática para quê? Didática para quem? Reflexões a partir de seu objeto. In: ENCONTRO NACIONAL DE DIDÁTICA E PRÁTICA DE ENSINO - Endipe, 17., 2014, Fortaleza. Fortaleza, 11 a 14 de novembro de 2014. 
FREITAS, Luiz Carlos de. Atividades Pedagógicas Remotas Nas Universidades Durante a Pandemia Disponível em: www.youtube.com/watch?v=mD0aJujD9IY\&feature=share\&fbclid=IwAR0gk2MR-S7lyEm-T5pax39NU-EwZj5xCLjXpEQrjTbL5bCRSoAJe75FBYo. Acesso em: 15 de maio de 2020.

FREITAS, L. C. de. Os reformadores empresariais da educação: da desmoralização do magistério à destruição do sistema público de educação. Educação e Sociedade, Campinas, v. 33, n. 119, p. 379-404, abr.jun.2012.

GHEDIN, E. A articulação entre estágio-pesquisa na formação do professor-pesquisador e seus fundamentos. In: BARBOSA, R. L. L. (Org.). Formação de educadores: artes e técnicas - ciências e políticas. São Paulo: Editora Unesp. 2006. p. 225-246.

GHEDIN, E. Professor reflexivo: da alienação da técnica à autonomia da crítica. In: PIMENTA, S. G.; GHEDIN, E. (Orgs.). Professor reflexivo no Brasil: gênese e crítica de um conceito. 5. ed. São Paulo: Cortez, 2008. p. 129-150.

GHEDIN, E.; ALMEIDA, W. A. de. O estágio com pesquisa na formação do professor-pesquisador para o ensino de ciências numa experiência campesina. In: GOMES, M. de O. (Org.). Estágios na formação de professores: possibilidades formativas entre ensino, pesquisa e extensão. São Paulo: Edições Loyola, 2011. p. 47-78.

GOMES, M. de O. (Org.). Estágios na formação de professores: possibilidades formativas entre ensino, pesquisa e extensão. São Paulo: Edições Loyola, 2011.

GOMES, M. de O. et al. Residência pedagógica: diálogo permanente entre a formação inicial e a formação contínua de professores e pedagogos. In: GOMES, M. de O. (Org.). Estágios na formação de professores: possibilidades formativas entre ensino, pesquisa e extensão. São Paulo: Edições Loyola, 2011. p. 15-46.

LEITE, Y. U. F. A construção dos saberes docentes nas atividades de estágio nos cursos de licenciatura. In EGGERT, E., TRANSVERSINI, C., PERES, E., BONIN, I. (Orgs.). Trajetórias e processos de ensinar e aprender: didática e formação de professores. Porto Alegre: EDIPUCRS, 2008. v. 1, p. 747-765.

LIMA, M. S. L. Estágio e aprendizagem da profissão docente. Brasília: Liber Livro, 2012.

LIMA, M. S. L.; AROEIRA, K. P. O estágio curricular em colaboração, a reflexão e o registro reflexivo dos estagiários: um diálogo entre a universidade e a escola. In: GOMES, M. de O. (Org.). Estágios na formação de professores: possibilidades formativas entre ensino, pesquisa e extensão. São Paulo: Edições Loyola, 2011. p. 117-134.

NAKANO, M.; ANCASSUERD, M. P. Estágio: memória e produção de conhecimento. In: GOMES, M. de O. (Org.). Estágios na formação de professores: possibilidades formativas entre ensino, pesquisa e extensão. São Paulo: Edições Loyola, 2011. p. 187-200.

OSTETTO, L. E. Deslocamento, aproximações, encontros: estágio docente na educação infantil. In: GOMES, M. de O. (Org.). Estágios na formação de professores: possibilidades formativas entre ensino, pesquisa e extensão. São Paulo: Edições Loyola, 2011. p. 79-98.

PANIZZOLO, C. A brinquedoteca universitária como espaço lúdico e de pesquisa para a formação de professores: desafios e possibilidades. In: GOMES, M. de O. (Org.). Estágios na formação de professores: possibilidades formativas entre ensino, pesquisa e extensão. São Paulo: Edições Loyola, 2011. p. 99-116. 
PÉREZ-GOMES, A. O pensamento prático do professor: a formação do professor como profissional reflexivo. In: NÓVOA, A. (Coord.). Os professores e sua formação. Lisboa: Publicações Dom Quixote, 1992. p. 93-138.

PFPUSP. Programa de Formação de Professores da Universidade de São Paulo. São Paulo, 2004. Disponível em: http://www4.fe.usp.br/wp-content/uploads/programa-de-formacao-de-professores/ programa-de-formacao-de-professores.pdf Acesso em: 21 setembro 2020.

PIMENTA, S. G. Formação de professores: identidade e saberes da docência. In: PIMENTA, S. G. (Org.). Saberes pedagógicos e atividade docente. 7. ed. São Paulo: Cortez, 2009a. p.15-34.

PIMENTA, S. G. O estágio na formação de professores: unidade teoria e prática? 8. ed. São Paulo: Cortez, 2009b.

PIMENTA, S. G. Pesquisa-ação crítico-colaborativa: construindo seu significado a partir de experiência de formação docente. Educação e Pesquisa, São Paulo, v. 31, n. 3, p. 521-539, set./ dez. 2005.

PIMENTA, S. G. Professor reflexivo: construindo uma crítica. In: PIMENTA, S. G.; GHEDIN, E. (Orgs.). Professor reflexivo no Brasil: gênese e crítica de um conceito. 5. ed. São Paulo: Cortez, 2008. p. 17-52.

PIMENTA, S. G. Projeto pedagógico e identidade da escola. In: PIMENTA, S. G. De professores, pesquisa e didática. Campinas: Papirus, 2001. p. 59-75.

PIMENTA, S. G. Relatório de Gestão - 2006-2009. São Paulo: Pró-Reitoria de Graduação Universidade de São Paulo, nov. 2009c.

PIMENTA, S. G.; LIMA, M. S. L. Estágio e docência. 5. ed. São Paulo: Cortez, 2017.

RIOS, T. A. É possível formar professores sem a Didática? In: ANAIS DO XVII ENDIPE - ENCONTRO NACIONAL DE DIDÁTICA E PRÁTICA DE ENSINO - Didática e Prática de Ensino - Didática e a prática de ensino: DIÁLOGOS SOBRE A Escola, a Formação de Professores e a Sociedade. edUECE, 2014, Livro 4. p. 00643-00653. Disponível em: http://uece.br/endipe2014/ index.php/2015-02-26-14-09-14?limit=5\&start=5. Acesso em: 25 de setembro de 2020.

SANTOS, O. J. dos. Pedagogia dos conflitos sociais. Campinas, SP: Papirus, 1992.

SAVIANI, D. Formação de professores: aspectos históricos e teóricos do problema no contexto brasileiro. Revista Brasileira de Educação, Rio de Janeiro, v. 14, n. 40, p. 143-155, jan./abr. 2009.

SAVIANI, D. Escola e democracia. São Paulo: Cortez; Campinas: Autores Associados, 1986.

SILVESTRE, M. A. Sentidos e significados dos estágios curriculares obrigatórios: a fala do sujeito aprendente. In: GOMES, M. de O. (Org.). Estágios na formação de professores: possibilidades formativas entre ensino, pesquisa e extensão. São Paulo: Edições Loyola, 2011. p. 165-186.

SILVESTRE, M. A., VALENTE, W. R. Professores em Residência Pedagógica: estágio para ensinar Matemática. Petrópolis, RJ: Vozes, 2014.

ZEICHNER, K. M. Uma análise crítica sobre a "Reflexão como conceito estruturante na formação docente”. Educação \& Sociedade, Campinas, v. 29, n. 103, p.535-554, maio/ago. 2008. Disponível em: http://www.cedes.unicamp.br. Acesso em: 15 de julho de 2010. 